\title{
STRUCTURE, MORPHOLOGY AND GROWTH OF BIOGENIC GREIGITE $\left(\mathrm{Fe}_{3} \mathrm{~S}_{4}\right)$
}

\author{
B.R. Heywood ${ }^{\mathrm{a}}$, S. Mann ${ }^{\mathrm{a}}$ and R.B. Frankel
}

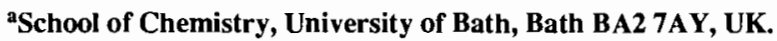

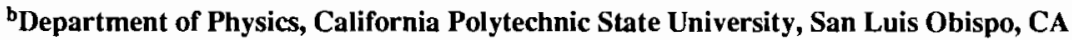

93407, USA.

\section{ABSTRACT}

Several species of aquatic bacteria are known to exploit the earth's geomagnetic field as a means of directing their motion towards suitable habitats. A feature common to these bacteria is the presence of discrete intracellular magnetic inclusions, magnetosomes, aligned in chains along the long axis of the organism. The size and orientation of the individual magnetic particles imparts a permanent magnetic dipole moment to the cell which is, in turn, responsible for the magnetotactic response. In all species examined to date the magnetic particles have been found to be well-ordered, single domain, membrane-bounded crystals with reproducible, species-specific morphologies. Until recently, however, only crystals of the mixed valence iron oxide, magnetite $\left(\mathrm{Fe}_{3} \mathrm{O}_{4}\right)$, were identified in these magnetotactic bacteria. We have now identified three species of bacteria from sulphidic environments which contain crystals of the mixed valence ferrimagnetic iron sulphide, greigite $\left(\mathrm{Fe}_{3} \mathrm{~S}_{4}\right)$. High resolution electron microscopical studies of the biogenic greigite crystals showed that they also exhibit the narrow size range (50-90 $\mathrm{nm}$ ) and unique crystallographic habits (e.g. cubo-octahedral, rectangular prismatic) which characterized and distinguished the inclusions in other magnetotactic species. Thus, it would appear that the bio-precipitation of iron sulphides in magnetotactic bacteria is a highly regulated process which is directed and controlled at the molecular level. These findings are not only important to our understanding of biomineralization in unicellular organisms but may also be significant to studies of paleomagnetism. Furthermore, the controlled synthesis of greigite presents an interesting challenge to material scientists and solid state chemists.

\section{INTRODUCTION}

The development of effective strategies for the reproducible control of crystal structure, size and morphology is attracting considerable attention given the requirement for particles of modal size and shape in many area of materials fabrication and the importance of crystallochemical specificity in determining the exploitable properties (e.g. optical, magnetic, electrokinetic) of inorganic solids. In biological systems there are many examples of advanced "crystal engineering" in which inorganic solids are deposited in a highly controlled manner to produce mineral phases that are unique with respect to their structure and habit, and uniformity of size. The crystallochemical specificity of such biogenic solids is tailored to a wide variety of 
both structural (e.g. bones, teeth) and non-structural roles. Examples of the latter include pH homeostasis, the transduction of magnetic signals and inertial detection. It is clear, therefore, that much can be gained from a study of the biochemical and biophysical mechanisms underlying biomineralization.

In this respect one biomineralizing system which has received much attention is the unique prokaryotic organisms which use the earth's geomagnetic field to direct their motions toward habitats most suitable for their survivial. A common feature of these magnetotactic bacteria is the presence of discrete intracellular magnetic inclusions, magnetosomes, aligned in chains along the long axis of the organism. The size and orientation of these individual magnetic particles imparts a permanent magnetic dipole moment which is responsible for the magnetotactic response. Until recently only crystals of the mixed valence iron oxide, magnetite, $\left(\mathrm{Fe}_{3} \mathrm{O}_{4}\right)$, were identified in these bacteria. Now, however, magnetic iron sulphide minerals have been identified in magnetotactic bacteria collected from sulphidic environments $[1,2,3]$. Our recent structural studies on these crystals are summarized in the present paper.

In order to gain a better understanding of the crystal growth process in these organisms we have utilised high resolution analytical transmission electron microscopy (HRTEM) to study the crystallographic ultrastructure of the intracellular greigite. The potential of HRTEM as a tool for these investigations lies in the principle that for crystals of sufficient thickness $(<10 \mathrm{~nm})$ the phase contrast observed in an electron microscope recorded under specific conditions of defocus is closely related to the projection of the atomic potential distribution in crystalline solids. The contrast, regularity and coherency of the resolved lattice fringes across the crystal is a good indicator of the crystallographic order within the sample. Similarly structure imaging allows for the clear resolution of local areas of disorder and discontinuity arising from structural defects and variations in local composition with the result that growth phenomena and structural transformations can be studied at the atomic level. Thus, HRTEM analysis of bioinorganic solids holds the prospect for providing information about the processes of nucleation and growth of these crystals in the biological environment.

\section{MATERIALS AND METHODS,}

Bacteria were collected from jars of sulphide-rich sediment and water sampled from salt-marsh pools at the Neponset River and Woods Hole, Massachusetts, and at Morro Bay, California. Permanent magnets were placed on the sampling jars with the south magnetic pole positioned just above the water-sediment interface and bacteria that accumulated near the pole were drawn up with a Pasteur pipette and examined by light microscopy. The bacteria collected in this manner included the multicellular magnetotactic organism described previously as well as several morphological types of magnetotactic rod-shaped bacteria. The bacteria were subsequently deposited unstained on amorphous carbon films on nickel grids for electron microscopy and all analyses were performed on particles located within intact bacteria. All samples were examined in a JEOL 2000FX transmission electron microsocpe 
fitted with a tungsten filament and a goniometer. Experimental observations were carried out at $200 \mathrm{KeV}$ with objective apertures of $40 \mu \mathrm{m}$ and $80 \mu \mathrm{m}$ and point-to-point resolution of $2.5 \AA$ $\left(\mathrm{C}_{\mathrm{s}}=1.2 \mathrm{~mm}\right)$ and $2.8 \AA\left(\mathrm{C}_{\mathrm{s}}=2.2 \mathrm{~mm}\right)$, respectively. To minimize the effects of radiolytic damage upon samples the intensity of the electron beam was kept as low as possible and all focusing and astigmatism corrections performed on areas of carbon-film adjacent to the crystals of interest. A liquid nitrogen cooled anticontamination device was used at all times. Dimensional measurements were taken from photographic enlargements of suitable HRTEM negatives. The electron diffraction patterns and fringe spacings were indexed by comparing their $\mathrm{d}$-spacings and interplanar angles with calculated values and published data assuming for greigite, a cubic unit cell (space group Fd3m) $a=9.86 \AA$, and pyrite, a cubic unit cell (space group $\mathrm{Pa} 3$ ) $a=5.41 \AA$.

\section{RESULTS}

Transmission electron micrographs of three different types of iron-sulphide containing magnetotactic bacteria are shown in Figure 1. One type was a large motile multicellular spherical organism composed of 7-20 individual ovoid cells. Each of these units contained about 10 discrete intracellular particles arranged in chains (Figure 1a). There was also some evidence for the consensus alignment of these chains throughout the whole multicellular aggregate. A second cell type (Figure 1b) was a small, unicellular (ca. $2.5 \mu \mathrm{m} \times 1.3 \mu \mathrm{m}$ ) organism with a single chain of, on average, 26 well-defined cuboidal electron dense particles of mean dimension, $67 \mathrm{~nm}$. Figure 1c illustrates a typical example of a larger ( $c a .3 \mu \mathrm{m} \mathrm{x} 2$ $\mu \mathrm{m})$ unicellular rod-like magnetotactic prokaryote with chains and clusters of predominantly rectangular electron dense particles. Individual cells contained approximately 57 crystals of mean dimensions $69 \mathrm{~nm} \times 50 \mathrm{~nm}$ with a variable aspect ratio (1.0 to 2.0). These crystals exhibited well-defined end faces but the sides were often irregular. Elemental mapping of all three organisms by scanning EDXA (data not shown) revealed that the electron dense intracellular particles consisted of iron and sulfur but not oxygen $[1,3]$.

\section{Electron diffraction data}

Identification of the mineral phase in all cell types was made by indexing single crystal electron diffraction patterns and lattice images of individual particles. This was necessary because the $d$-spacings of all the iron sulfides are similar, making identification from limited powder diffraction data alone unreliable. A single crystal electron diffraction pattem from a rectangular particle in the larger rod-shaped bacterium is shown in Figure 2a. The pattern corresponds to the $\langle 100\rangle$ zone of greigite, $\left(\mathrm{Fe}_{3} \mathrm{~S}_{4}\right)$. Superposition of the pattem and corresponding image (see inset) indicates that the crystals are elongated along one of the $a$ axes and the well-defined end faces and less regular side faces are of $\{100\}$ form. These observations were confirmed by crystallographic analysis of greigite particles aligned along 

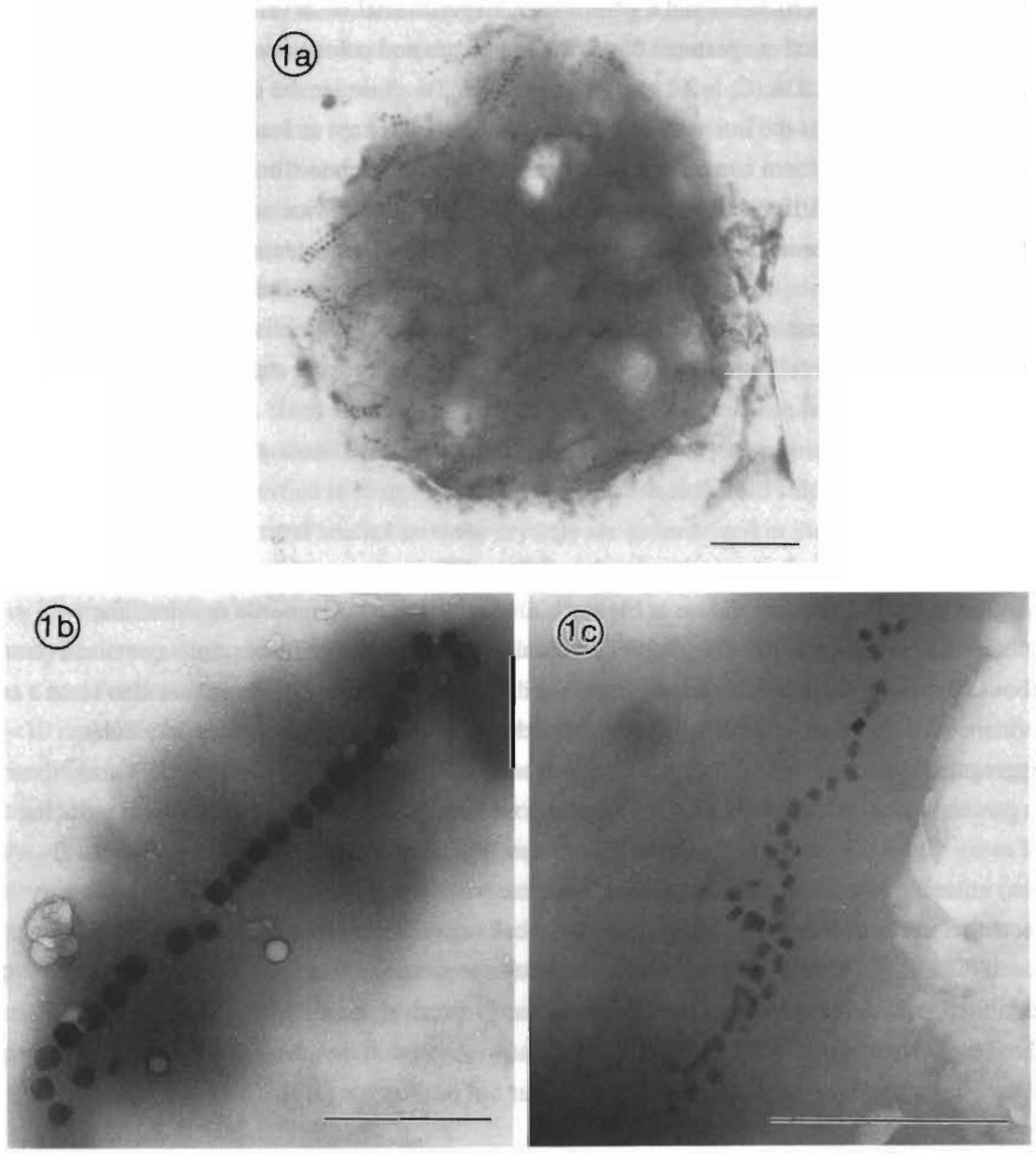

\section{Figure 1}

Transmission electron micrographs of the three types of magnetotactic bacteria collected from sulphidic environments. (a) A multicellular organism with numerous discrete intracellular iron sulphide particles. $\mathrm{Bar}=1 \mu \mathrm{m}$. (b) Unicellular rod-shaped bacteria containing electron dense cubo-octahedral inclusions. Bar $=1 \mu \mathrm{m}$. (c) Large rod-shaped unicellular organism containing rectangular iron sulphide particles. $\mathrm{Bar}=500 \mathrm{~nm}$. 

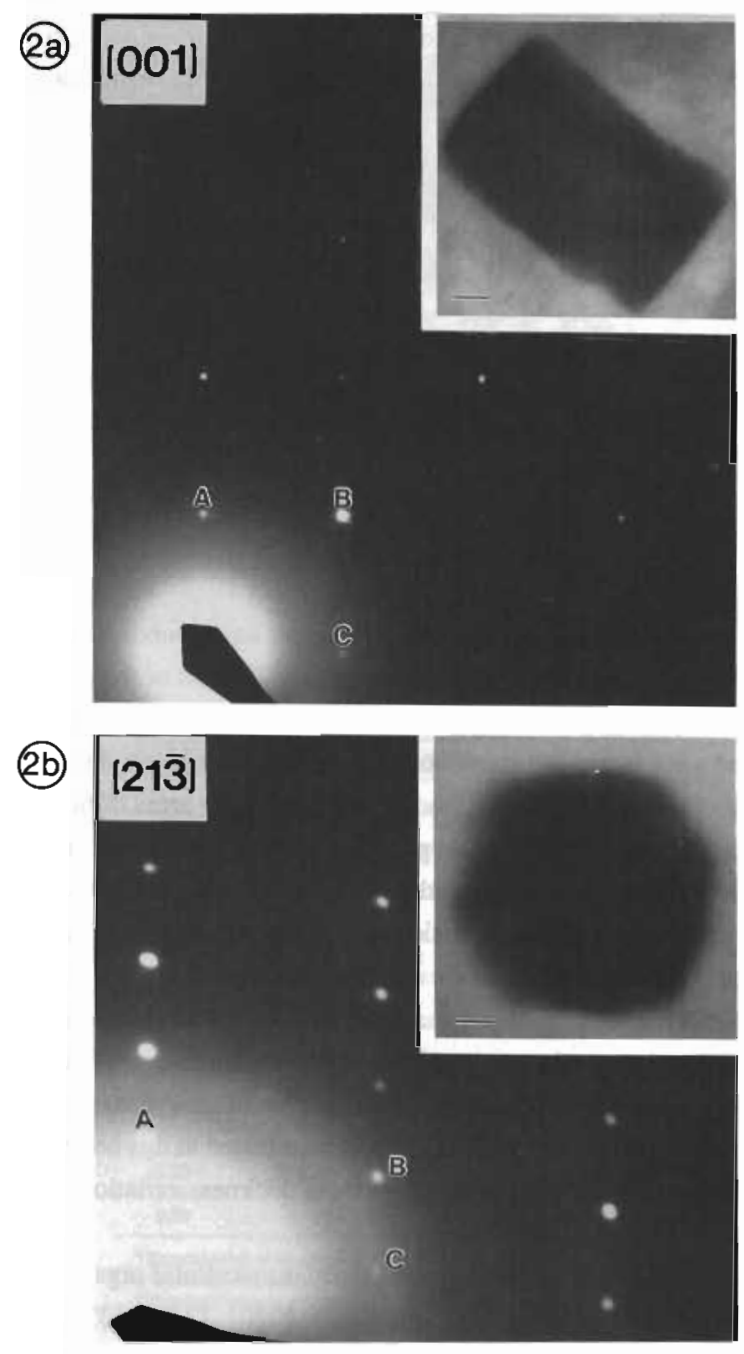

\section{Figure 2}

Single crystal greigite $\left(\mathrm{Fe}_{3} \mathrm{~S}_{4}\right)$ electron diffraction patterns recorded from iron sulphide inclusions in unicellular organisms and associated images (insets). (a) Prismatic rectangular

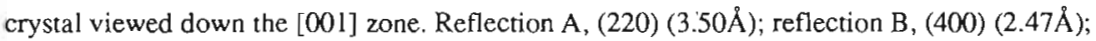
reflection $C,(2 \overline{2} 0)(3.50 \AA)$; Angles: $(220) \wedge(400)=45^{\circ} ;(220) \wedge(2 \overline{2} 0)=90^{\circ}$. (b) Cubo-octahedral

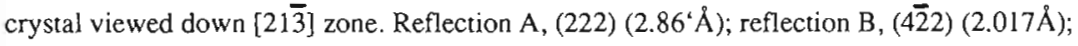
reflection $C,(3 \overline{3} 1)(2.28 \AA)$ Angles: $\left.(222 \wedge 4 \overline{2} 2)=61.5^{\circ} ; 222 \wedge 3 \overline{3} 1=82.3^{\circ}\right)$. Scale bars (insets) = $10 \mathrm{~nm}$. 
different directions, eg. $\langle\overline{1} 12\rangle$ and $\langle 2 \overline{1} \overline{5}\rangle,\langle 110\rangle$, and by lattice imaging (see below). Thus the crystals have an idealized morphology based on a rectangular prism of six cubic $\{100\}$ faces.

Single crystal electron diffraction patterns from particles in the smaller rod-shaped bacteria were also indexed to greigite (Figure $2 b$ ). Diffraction patterns corresponding to the $\langle 112\rangle,\langle 21 \overline{3}\rangle$, and $\langle 01 \overline{1}\rangle$ zones of greigite were obtained. Analysis of the diffraction patterns and associated images, as well as lattice images (see below) of the crystals indicated that the particles were cubo-octahedral in morphology with well-defined $\{111\}$ faces and smaller truncated $\{100\}$ faces.

Single crystal electron diffraction patterns obtained from crystals in the multicellular organism gave evidence for the presence of both greigite and pyrite crystals (data not shown) [1]. Powder pattern data indicated that pyrite may be the dominant crystalline form in these organisms (Figure 3) [1].

\section{HRTEM studies of crystal structure and morphology}

Lattice images of individual crystals showed fringes corresponding to the lattice planes of greigite: the $d$ spacings and angles between two non-parallel sets of fringes were consistent with the cubic ( $\mathrm{Fd} 3 \mathrm{~m}$ ) space group of this mineral. The recorded fringes were generally regular and well-defined and were in general continuous throughout the crystals thus confirming the single crystal nature of these particles. No amorphous domains or areas of bulk disorder were identified within any of the crystals. In many particles, however, there were regions of varying contrast extending along the $\{111\}$ planes with a thickness of approximately $10 \AA$ (see Figure 4). These probably represent lattice imperfections attributable to stacking faults or local deviations of the chemical composition of these close packed planes. These defects were particularly prevalent in the rectangular prismatic crystals. It was also noted that the small cuboidal crystals exhibited marked variations in diffraction contrast across the imaged surface such that the crystals were bisected along the $\langle 100\rangle$ axis by an abrupt change in electron density (see Figure 4). Since lattice fringes frequently terminated at this boundary it is suggested that the change in electron density arises from thickness variations in the crystals produced by steps and surface irregularities.

A lattice image typical of crystals from the smaller unicellular organism is shown in Figure 4. Lattice fringes corresponding to $\{111\},\{200\},\{220\},\{310\},\{320\}$ and $\{321\}$ planes were imaged on these crystals and the $\langle 1 \overline{1} 0\rangle$ zone was predominant. Furthermore, it was concluded from the fringes parallel to the particle edges that the crystals were faceted. These observations were consistent with the assignment of an idealized crystal habit based on an octahedral prism of \{111\} faces truncated by small (100\} faces (Figure 6) [4].

HRTEM images of the crystals from the larger of the unicellular magnetotactic organisms consistently revealed lattice fringes corresponding to $\{111\},\{200\},\{220\},\{310\}$, \{311\} \{320\}, \{321\} and $\{400\}$ lattice planes of greigite. From these images it was determined that the crystals were bounded by well-defined $\{100\}$ faces at their termini and a series of 

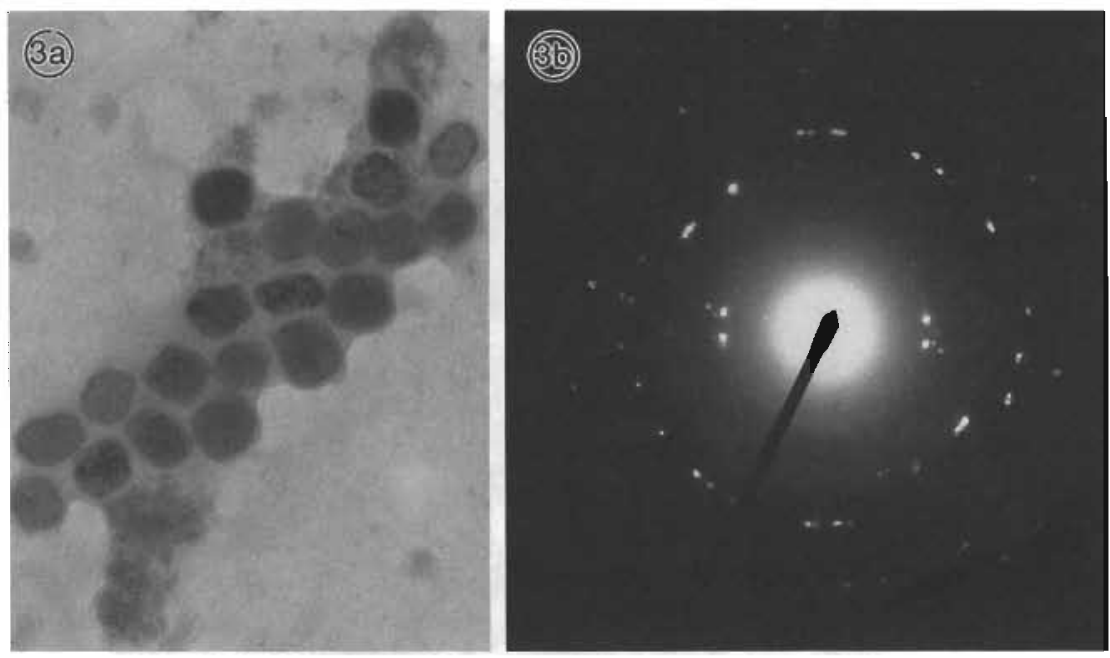

(3c)

\begin{tabular}{|c|c|c|c|c|}
\hline \multirow[b]{3}{*}{ Data* } & \multicolumn{4}{|c|}{$\begin{array}{l}\text { Electron diffraction data and identification of bacterial } \\
\text { Fe sulphice inclusions }\end{array}$} \\
\hline & \multirow{2}{*}{\multicolumn{2}{|c|}{ Source $\dagger$}} & \multicolumn{2}{|c|}{ Assignment; } \\
\hline & & & greigite & pyrite \\
\hline 3.57 & & $s$ & $3.50(220)$ & \\
\hline 3.16 & $\mathbf{R}$ & $\mathrm{s}$ & & 3.128 (111) \\
\hline 3.06 & & $\mathrm{~s}$ & 2.98 (311) & \\
\hline 2.69 & $\mathbf{R}$ & & & $2.709(200)$ \\
\hline 2.51 & $\mathrm{R}$ & & $2.470(400)$ & \\
\hline 2.28 & & s & 2.26 (331) & \\
\hline 2.12 & $\mathbf{R}$ & & & 2.211 (211) \\
\hline 2.04 & & s & $2.017(422)$ & \\
\hline 1.89 & $\mathbf{R}$ & s & 1.901 (333) & $1.915(220)$ \\
\hline 1.71 & $\mathrm{R}$ & & $1.746(440)$ & \\
\hline 1.65 & & s & 1.671 (531) & \\
\hline 1.60 & $\mathbf{R}$ & s & & $1.633(311)$ \\
\hline 1.55 & & s & & 1.564 (222) \\
\hline 1.35 & $\mathbf{R}$ & & $1.383(711)$ & $1.354(400)$ \\
\hline 1.26 & & s & 1.286 (731) & \\
\hline 1.22 & $\mathbf{R}$ & & $1.235(800)$ & $1.211(420)$ \\
\hline 1.07 & R & $\mathrm{s}$ & $1.054(664)$ & $1043(333)$ \\
\hline 0.89 & & $\mathrm{~s}$ & & $0.903(600)$ \\
\hline
\end{tabular}

* Experimental d spacings in $\AA$

$\uparrow R$, powder ring pattern; $S$, single crystal pattern.

₹ Standard mineral $d$ spacings in $\mathcal{A}$. X-ray powder diffraction file: greigite (16-713), and pyrite (6-710), (hkl), Miller indices.

\section{Figure 3.}

Transmission electron micrograph of the biogenic crystals formed in a magnetotactic multicellular aggregate (a) with associated electron diffraction pattern (b). Single crystal and powder diffraction data confirmed the presence of both pyrite and greigite in these organisms (c). 


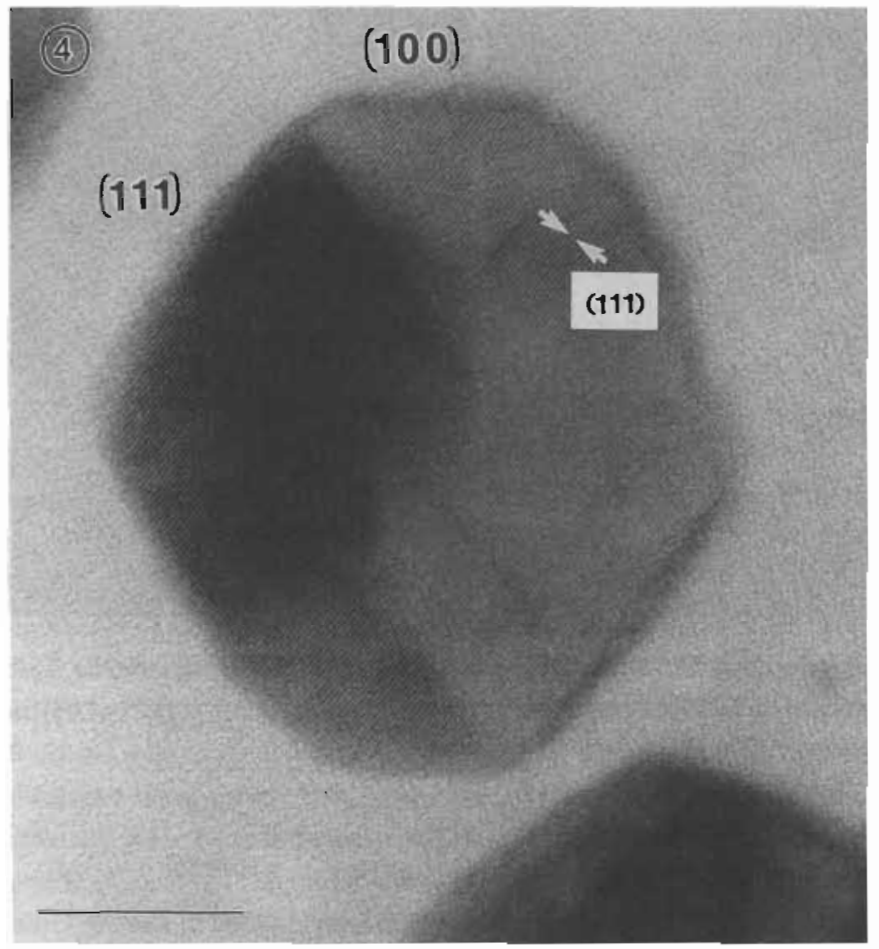

\section{Figure 4.}

HRTEM image of a greigite crystal from a chain of particles in a small unicellular organism. The crystal is oriented along the [011] direction and exhibits a characteristic morphology based on an octahedral prism of $\{111\}$ faces truncated by $\{100\}$ faces. The lattice finges correspond to the (111) planes of the greigite lattice. Bar $=20 \mathrm{~nm}$.

\section{Figure 5.}

HRTEM electron micrograph of a rectangular prismatic crystal from a large unicellular magnetotactic organism. The crystal is oriented along the [001] zone. The crystal is bounded by two-well defined $\{100\}$ faces at each end and the corners are truncated by small $\{111\}$ faces. A series of structural defects $(\Uparrow)$ along the $\{111\}$ planes are clearly imaged. 


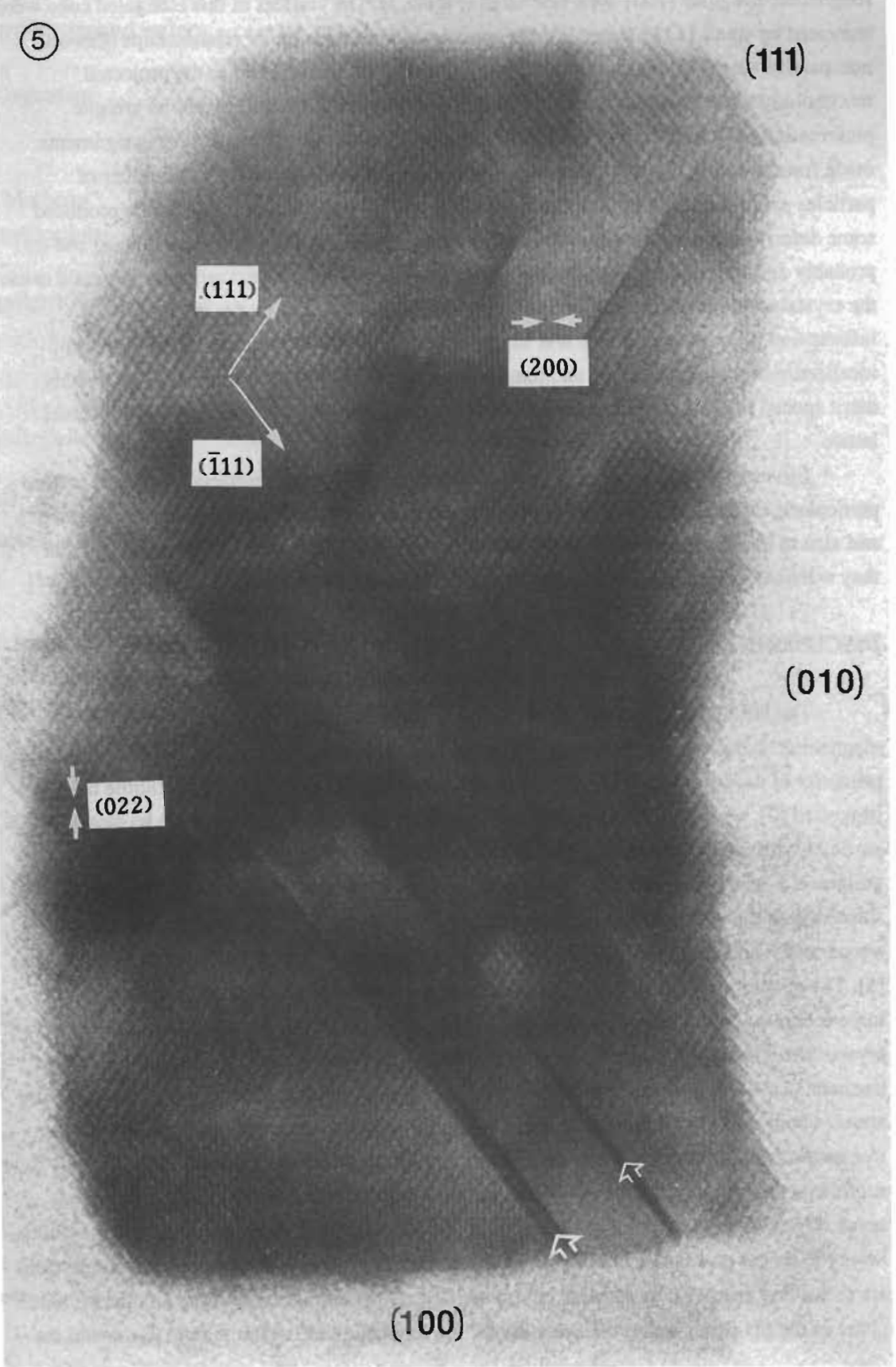


roughened, irregular $\{100\}$-type side faces (Figure 5). The vertices of this elongated cube were truncated by small $\{111\}$ faces. From a consideration of the angular relationships between non-parallel sets of fringes and their relative orientations with respect to the projected morphology of the particles it was confirmed that the particles were crystals of greigite preferentially elongated along the $<1.00\rangle$ direction. This is consistent with the assignments made from the single crystal electron diffraction patterns (see above) [3]. A number of particles exhibited kinks and bulges at about the mid-point of the long axis which produced some deformation and occasionally bending of the crystals. No crystals were imaged end-on probably as a result of the physical elongation and the resultant aspect ratio which would cause the crystals to lie preferentially on the larger side faces of the prism. On the basis of information accumulated to date it is suggested that these rectangular crystals express an idealized morphology based on an elongated truncated cubic habit (Figure 6). The crystals merit special interest since they do not conform to the symmetry relations of the thiospinel lattice.

Structural imaging of the crystals in the multicellular magnetotactic aggregate proved particularly difficult. This was attributed to the thickness of the crystals in the first instance and also to their irregular shapes. The few lattice images which were recorded showed that they were crystallographic single-domain particles based on a cubic-derived morphology [1].

\section{DISCUSSION}

The HRTEM images and electron diffraction data have confirmed that the magnetotactic bacteria inhabiting sulphidic environments contain chains of crystals composed primarily of the magnetic iron sulphide greigite. Although the presence of pyrrhotite has been suggested [2], we have found no evidence to support this. A comparison of the biogenic particles with their synthetic and geological homologues indicates that the bioprecipitation of greigite is a strictly regulated process. Greigite is not a thermodynamically stable form of iron sulphide and the preparation of a pure crystalline sample requires stringent anoxia, high temperatures and controlled quenching in order to limit the occurrence of other iron sulphides [5]. The resulting crystals are thin plates with an essentially cubic morphology. Lattice

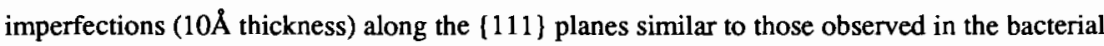
crystals are a consistent feature of the synthetic crystals (see Figure 7) [6]. Biogenic greigite has been identified previously in the sediments generated by chemolithotrophic bacteria under anoxic conditions [7]. Thiopneuts release $\mathrm{H}_{2} \mathrm{~S}$ into the environment where it reacts with any free metals present at sufficient solution concentration to effect precipitation. The sulphate-reducing bacteria, Desulfovibrio spp., have been credited with producing at least seven different iron sulphides including hydrotroilite, pyrite and mackinawite [7]. The bacteria, however, do not participate directly in the mineraliztion process and the precipitation reactions are controlled primarily by ambient environmental $\mathrm{pH}$ [8]. Greigite occurs as an intermediate phase in the $\mathrm{pH}$-dependent transformation of iron monosulphide to framboidal pyrite and the 
Table 1: Biosynthesis of intracellular iron sulphides by bacteria from sulphide-rich sediments and waters.

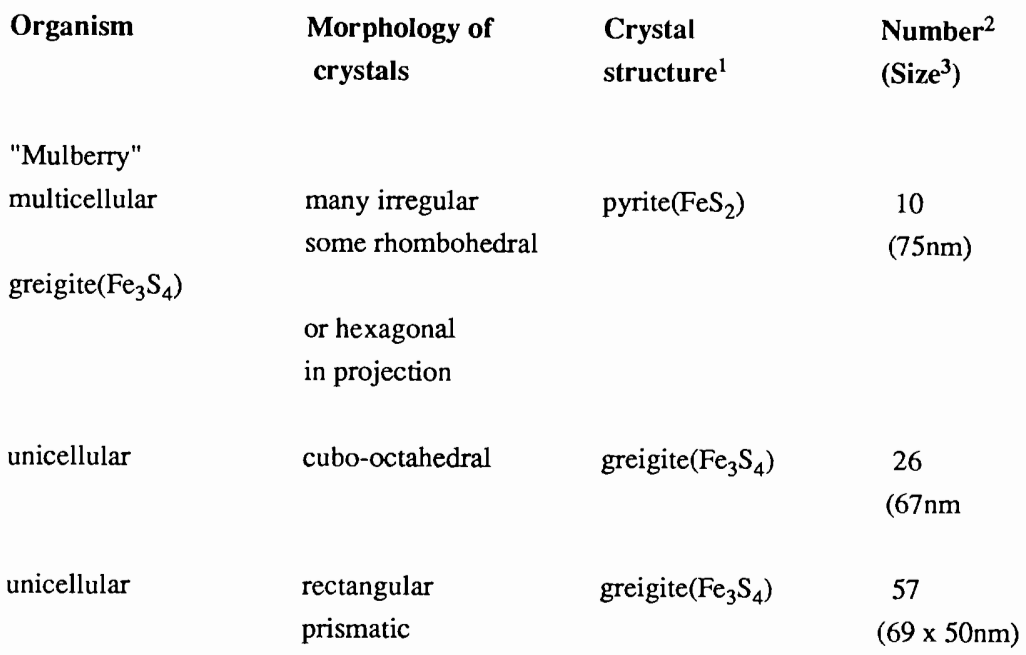

1. Identified from electron diffraction data.

2. Average number of intracellular crystals per chain.

3. Mean size of crystals.
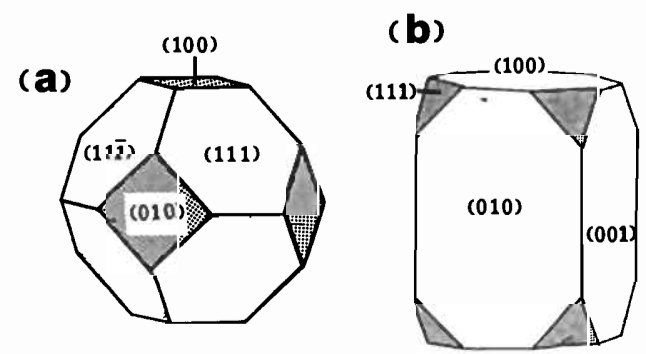

Figure 6.

Idealized morphologies of greigite crystals formed in magnetotactic bacteria:(a) cubo-octahedron, (b) an elongated, truncated cube. 


\section{Figure 7.}

HRTEM electron micrograph of synthetic greigite prepared by the method of Horiuchi et al, [6]. Note the presence of structural defects along the $\{111\}$ planes $(\Uparrow) . \mathrm{Bar}=10 \mathrm{~nm}$.

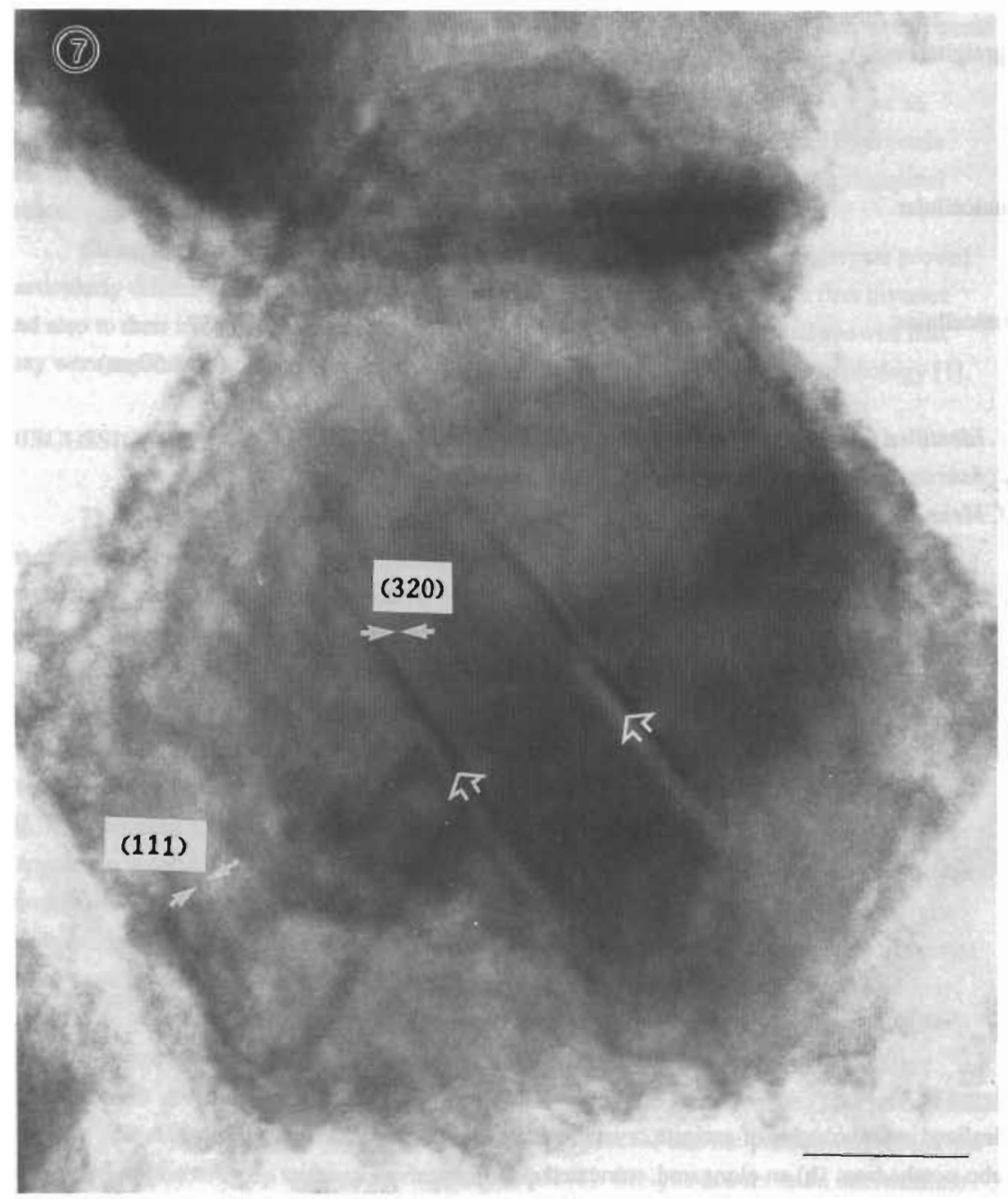


particles so-formed are small, irregular and crystallographically ill-defined. It should be noted that the extracellular magnetite particles produced by dissimilatory non-magnetotactic iron-reducing bacterium, (strain GS-15), under anaerobic conditions are also structurally and morphologicaly indistinct [9]. Finely grained particles of abiogenic greigite with no specific morphological characteristics have been extracted from metalliferrous sediments of both recent and ancient origins, where it is one of a series of iron sulphides formed under reducing conditions during diagenetic and post-diagenetic sulphide mineralization, viz. pyritization [10]. Another source of magnetic, cubic iron sulphide is the ore minerals deposited from the metal-bearing brines associated with $\mathrm{H}_{2} \mathrm{~S}$-discharging hydrothermal systems [11,12]. In this case the mineral greigite, (melnikovite, [13]) occurs either as balls ( $\sim 0.33 \mathrm{~mm}$ diameter) of intergrown octahedra with curved faces, rounded segregations (200-500 $\mu \mathrm{m}$ diameter) or acicular grains $(<1 \mu \mathrm{m})$, and is commonly associated with pyrite and marcasite deposits [14]. It is clear, therefore, that the occurrence of greigite as discrete well-formed crystals with regulated morphologies and size in magnetotactic bacteria represents a unique example of solid state bioengineering.

Interestingly, the rod-shaped bacteria appear to maintain greater control over mineralization compared with the multicellular organism. The latter produces crystals of both greigite and pyrite $\left(\mathrm{FeS}_{2}\right)$ and the morphologies are not well-defined. By contrast, the rod-shaped bacteria specifically mineralize greigite and regulate the crystal habit. Since the structure, size and morphology of these crystals is apparently well-regulated, these results in conjunction with previous observations suggest that the biomineralization of greigite like the formation of intracellular magnetite is under biological control. Furthermore, the identification of unique and species-specific morphologies in both systems argues strongly for the employment of similar crystallochemical strategies in their formation.

Species-specific morphologies have already been ascribed to the crystals formed by a number of magnetite-producing magnetotactic bacteria [15]. In Aquaspirillum magnetotacticum, for example, the magnetic particles are truncated octahedra, while in other bacteria, particles with morphologies based on hexagonal prisms and bullet-shaped or arrowhead geometries are observed [15]. The expression of such unique crystal morphologies gives evidence of the interrelated chemical, spatial and structural factors which control the bioprecipitation of magnetite in these organisms and there is now a growing body of evidence which indicates that intracellular magnetite biomineralization is directed by a hierarchy of interrelated molecular interactions [15]. Critical to these biologically-mediated crystallochemical processes is the organic trilaminate magnetosome membrane which provides (1) an enclosed microenvironment for the precipitation reactions, (2) the potential for chemical specificity via selective ion-transport, and (3) imposes geometric constraint upon the growing crystals. As a charged, ordered organic surface the membrane may also exert control over the sequelae of kinetic and structural events associated with nucleation [16].

The deposition of cubo-octahedral crystals (Figures 1 and 4) probably reflects the formation of an equilibrium habit involving minimal biological intervention: the growth 
process being directed merely by the flux of the reactant ions into a vesicular compartment at a rate commen surate with controlled growth [15]. Although the existence of an organic membrane around the biogenic greigite crystals has yet to be confurmed, HRTEM images of many crystals suggested the presence of such a structure in close proximity to the crystals. The formation of the elongated rectangular crystals is of greater interest since the symmetry relationships of the isometric lattice have been broken during biosynthesis to produce this unique habit. Furthermore the potential involvement of molecular mechanisms in the formation of the rectangular greigite crystals is suggested by the association of a preferred crystallographic axis $(<100>)$ with the direction of elongation. This observation in particular is significant since the $<100\rangle$ crystal axis is also the easy axis of magnetization in greigite [17].

Since the crystal habit of inorganic solids can be a reflection of the spatial and chemical environment in which they were formed, the expressed morphology of the rectangular prismatic greigite crystals suggests that their growth is mediated by biologically-imposed geometric and/or crystallochemical conditions. One possibility is that the crystals develop within vesicles that are extended along one direction, imposing a spatial constraint upon the forming crystals during growth. The fact that both the terminal $\{100\}$ faces are well-defined while the side faces are distinguished by their irregularity, (see Figure 5) lends some support to this proposal. Chemical regulation ( $\mathrm{pH}$, degree of supersaturation, solution composition, redox gradients, etc.) of the vesicular environment is also a potential tool for selecting and optimising the conditions for bioprecipitation. For instance the site-directed flux of ions or growth modifiers into the compartment would favour the nucleation and growth of one set of symmetry-related faces over another [15]. Such a process would depend upon the selective localization of ion-transport systems at specific loci in the vesicular membrane. Similar mechansims have been invoked to explain the formation of intracellular magnetite crystals in magnetotactic bacteria [15]. In the context of the above, it is also interesting to note that (1) two unique proteins have now been isolated from the magnetosome membrane of magnetite-forming bacteria [18], and (2) that an ion-translocating proteolipid which is also capable of initiating membrane-mediated calcium phosphate deposition has been isolated from the membrane of the calcifying bacteria Bacterionema matruchotii [19].

These HRTEM studies have confirmed that the biogenic greigite crystals are formed as single domain particles. On the basis of this and other information it is possible to calculate the average permanent magnetic dipole per cell [20]. A greigite density of $4.1 \mathrm{~g} / \mathrm{cm}^{3}$ from the crystallographic data (space group, $\mathrm{Fd} 3 \mathrm{~m}, a=9.88 \AA, 8$ formula units per unit cell) and a measured saturation magnetization of $30 \mathrm{emu} / \mathrm{g}$ yields a permanent magnetic dipole moment per particle, $m=3.65 \times 10^{-14} \mathrm{emu}$. For particles arranged in a chain, the total moment is the sum of the individual particle moments [20]. Thus, for a unicellular organism with an ordered chain of 26 cubooctahedral particles the total moment, $M=9.5 \times 10^{-13} \mathrm{emu}$. In the geomagnetic field, $\mathrm{B}_{\mathrm{G}}=0.5$ gauss, the magnetic energy, $\mathrm{M} \times \mathrm{B}_{\mathrm{G}} \approx 4 \times 10^{-13} \mathrm{ergs}$, which is more than 10 times thermal energy at $300 \mathrm{~K}$. The chain of greigite particles has, therefore, a large enough permanent magnetic dipole moment so that the migration speed of the cell along 
geomagnetic field lines would be more than $80 \%$ of its forward speed. If some particles in the chain were non-magnetic pyrite, as they are in the case of the multicellular organism, the migration efficiency would be correspondingly reduced. Calculations of the average permanent magnetic dipole moment of the larger rod-shaped cells are more difficult because of the apparent clustering of the particles in some organisms. Organized chains of these elongated crystals are seen, however, and the crystals are crystallographically aligned so that the $\langle 100\rangle$ axis lies parallel with the direction of the chain. Since this is also the easy axis of magnetization the selective alignment of the rectangular crystals along this direction may have functional significance. Arguably this preferred ordering of the crystals would necessitate fewer crystals per organism. It is noted, however, that the organisms containing rectangular prismatic crystals actually synthesize more rather than less particles (see Table 1). We have observed that the greigite crystals of both biogenic and synthetic origin are frequently flawed by stacking faults and non-stoichiometric deviations along the close packed $\{111\}$ planes. Perhaps these lattice imperfections disrupt the electronic coupling responsible for generating the magnetic dipole within the crystal with the result that the net magnetic moment of the crystal is diminished. Hopefully, future research will qualify this issue.

The foregoing analysis suggests that the rod-shaped bacteria specifically mineralize greigite, not pyrite, in connection with magnetotaxis. This specificity argues against the view that intracellular greigite transforms to pyrite on a time scale comparable to the lifetime of the cell [1]. The presence of both greigite and pyrite in the multicellular bacterium suggests that this organism may be capable of simultaneously and separately mineralizing the two iron sulphides. Since pyrite does not contribute to the magnetotactic response, its role may be related to the maintenance of homeostasis of iron and/or sulphide, or to other metabolic processes in the cells.

\section{CONCLUDING REMARKS}

The controlled formation of single domain magnetic particles under low temperature conditions is of considerable technological interest especially since crystallochemical specificity is an important determinant of functional efficiency. There is much demand for tailored inorganic materials which have defined catalytic, magnetic, optical or electrokinetic properties. It is evident from a study of biomineralizing systems that biology has already overcome many of the practical problems attendent upon solid state crystal engineering. Thus it is hoped that new routes to the controlled synthesis and fabrication of technologically important materials will be forthcoming from the detailed analysis of such systems. 


\section{Acknowledgements}

Dr B R Heywood was supported by BP International Ltd., Professor R B Frankel by the US Office of Naval Research and Professor S Mann by the SERC (UK).

The authors would like to thank Dr D A Bazylinski for providing the bacterial samples and for helpful discussions. The assistance of Ms Alex Lynch in the preparation of the synthetic samples is gratefully acknowledged.

\section{REFERENCES}

1. Mann, S., Sparks, N. H. C., Frankel, R. B., Bazylinski, D. A. and Jannasch, H. W. Nature $\underline{343}, 258-261$ (1990).

2. Farina, M., Motta de Esquivel, D. and Lins de Barros, H. G. P. Nature $\underline{343}$, 256-258 (1990).

3. Heywood, B.R., Bazylinski, D. A., Garratt-Reed, A., Mann, S. and Frankel, R. B. Naturwissenschaften in press (1990)

4. Mann, S., Frankel, R. B. and Blakemore, R. P. Nature 310 405-407 (1984)

5. Berner, R. A. J. Geol. 72 293-306 (1964)

6. Horiuchi, S., Wada, H. and Moori, T. J Crystal Growth 24-25 624-626 (1974)

7. Hallberg, R. O. N. Jahrbuch Mineral Monatsohefte 481-500 (1972)

8. Freke, A. M. D. J Biochem. Microbiol. Tech. Eng.111 (1), 29-39 (1961)

9. Sparks, N. H. C., Mann, S., Bazylinski, D. A., Lovely, D. R., Jannasch, H. W. and Frankel R. B. Earth and Planetary Science Lett. 98, 14-22 (1990)

10. Cutter, G. A. and Velinsky, D. J. Marine Chemistry 23, 311-327 (1988)

11. Snowball, I. and Thompson, R. J Quaternary Science $\underline{3}$ (2), 121-125 (1988)

12. Russell, M. J., Hall, A. J. and Turner, D. Terra Nova 1, 238-24l (1989)

13. Doss, B. Beil Band Abt. $\underline{33}, 662-713$ (1912)

14. Williams, S. A. Amer Minerol 53, 2087-2088 (1968)

15. Mann, S. and Frankel, R. B. in Biomineralization: Chemical and Biochemical Perspectives (eds. Mann, S., Webb, J. and Williams, R. J. P.) 389-426 (VCH Weinheim, 1989).

16. Mann, S., Heywood, B. R., Rajam, S., Walker, J. B. A., Davey, R. J. and Birchall, J D. Advanced Materials 르, 257-261 (1990)

17. Yamaguichi, S. and Wada, H.J Applied Physics $\underline{41}$ (4), 1873-1874 (1970)

18. Gorby, Y. A., Beveridge, T. J. and Blakemore, R. P. J Bacteriol 170, 834-841 (1988)

19. Swain, L. D. and Boyan, B. D. J Dent Res, 67, 526-530 (1988)

20. Frankel, R. B. Ann. Rev. Biophys. Bioeng. 13, 85-103 (1984) 